\title{
¿Qué significa pensar moralmente? \\ Dos maneras actuales de entender a Kant: Robert B. Brandom y Jürgen Habermas
}

\author{
LUIS MARTÍNEZ DE VELASCO
}

RESUMEN. A los doscientos años del fallecimiento de Immanuel Kant, su influencia no hace sino crecer cada día que pasa. La nómina de filósofos pasados y presentes que han recibido, de alguna manera, herencias kantianas resulta difícilmente abarcable con la mirada. De entre todos estos filósofos destacan dos cuyo origen - filosofía analítica y pensamiento frankfurtiano, respectivamente - no parece delatar, en principio, la filiación kantiana de su pensamiento. $Y$, sin embargo, pocos pensadores han logrado captar como ellos la esencia problemática de la reflexión de Kant, sobre todo en lo concerniente a la autofundamentación de un pensamiento contrafáctico en el marco de una consideración pragmático-transcendental del uso del lenguaje. Nos referimos a Robert $\mathrm{B}$. Brandom y a Jürgen Habermas.

En Brandom la pregunta kantiana por el quid juris? constituye el núcleo de su reflexión sobre el lenguaje como vehículo de la fuerza normativa del acto de hablar. En Habermas es la propia constelación transcendental de la filosofía de Kant lo que viene a jugar el papel de columna vertebral que unifica y da sentido a todas aquellas nociones en que se despliega su teoría de la acción comunicativa! Por caminos algo diferentes, Brandom y Habermas expresan hoy la necesidad de recurrir
ABSTRACT. Two hundred years often I. Kant's death, his influence grows more and more each day. The list of such past and present philosophers as have received, in a way or another, the Kantian heritage cannot be easily encompassed. Among them all, there are two outstanding philosophers whose intellectual origin - analytic philosophy and Frankfurtian thought respectively - would not in principle betray any Kantian lineage. However they have been able to reach a rare mustering of the problematic essence of Kant's reflexion, chiefly as regards the self-grounding of counterfactual thought within the framework of a pragmatic-transcendental view of language use. We are referring to Robert B. Brandom and Jürgen Habermas.

a Kant, cuya reflexión es capaz de conservar y hacer prevalecer los motivos contrafácticos y a la vez posmetafísicos de una razón situada críticamente frente a una problemática vuelta a la religión (Kolakowski) así como frente al relativismo moral a que la conduce el indiferentismo ontológico del lenguaje propugnado por Rorty. Tanto Brandom como Habermas nos ofrecen, en este sentido, dos reconstrucciones que actualizan a Kant sin tornarlo irreconocible. Todo lo contrario: su 
vuelta a Kant subraya precisamente los aspectos más decisivos y comprometedores de una reflexión que, como dijera su autor, daría sus frutos cien años después de su muerte. A los doscientos años de ésta no cabe duda de que tales frutos siguen resultándonos imprescindibles.

\section{Kant y la geometría de la virtud}

De entre las tensiones que sostienen y vivifican la reflexión transcendental kantiana sobresale una por su importante vinculación al problema de las fuentes del conocimiento. Nos referimos a la tensión entre la imaginación y la razón ${ }^{2}$. Pese a la innegable articulación entre una y otra fuente en el terreno de lo real, conviene recordar y subrayar su profunda incompatibilidad transcendental, proveniente de la irreductible duplicidad entre las perspectivas que una y otra abren al conocimiento humano del universo. La imaginación sostiene una perspectiva antropocéntrica que, si bien resulta irrebasable en los terrenos de la Estética Transcendental (percepción) y la Analítica Transcendental (concepción), no lo es en absoluto en el campo acotado por la Dialéctica Transcendental. Aquí las antinomias de la razón pura abren una horquilla de interpretaciones (juicios) del universo que ponen de manifiesto no sólo la asimetría de los tipos de interpretación (Dios-Alma-Libertad versus Naturaleza-Materia-Necesidad), sino, sobre todo, un doble aspecto de decisiva importancia. Un aspecto pragmático que, atento a la conexión entre creencias (en general) y conductas (en general), consigue reflejar la diversidad de actitudes del sujeto a la hora de adherirse a uno u otro tipo de creencias metafísicas - pues se trata de creencias-, por ejemplo, la comodidad, la vanidad o la moralidad en la metafísica idealista (antropocéntrica) o la objetividad, la sobriedad o el escepticismo moral en la materialista (logocéntrica). Y un aspecto pragmático-transcendental (como región del primero) atento a la vinculación entre creencias y conductas en tanto que morales. En este segundo sentido, la actitud moral del sujeto, al renunciar a que sus temores y esperanzas gobiernen sus concepciones teóricas ${ }^{3}$, viene a reflejar una suerte de honradez (que, al instalarse en el plano de las creencias, debe calificarse de transcendental) que le exhorta a sostener una concepción teórica objetiva (en sentido transcendental), des-ilusionante, aun a riesgo de implicar, como por arrastre, una actitud moral escéptica. En efecto, Naturaleza-Materia-Necesidad no parecen animar precisamente a adoptar una visión moralmente idealista, y ello no ya sólo por la radical ausencia de una perspectiva vertebrada en torno a una idea general de «recompensa», sino también -y esto es para Kant aún más grave - por la anulación de la capital noción de libertad.

La fundamentación autónoma de la moralidad, el célebre «deber por el deber» kantiano (que no se refiere al contenido de la acción moral, o sea, a una abstracción que deja al sujeto sin saber qué hacer, tal y como lo interpreta Hegel un tanto maliciosamente, sino a que los motivos del obrar moral han de renunciar a cualesquiera resortes utilitaristas, es decir, heterónomos); la fundamentación autónoma de la moral, decimos, sólo puede llegar a resolver los problemas mencionados por medio de su propio despliegue interno. La honradez transcendental me impide tanto recurrir a la ilusoriedad de un universo ajustado a mis necesidades narcisistas como escamotear mi responsabilidad moral en base a tal desilusión: aunque Dios no exista no todo me está permitido, afirmación que supone, desde luego, no aceptar ni la falsa responsabilidad utilitarista de la ilusoriedad ni la franca irresponsabilidad del fatalismo. He de actuar moralmente aunque no consiga nada a cambio, aunque la Naturaleza no quiera que mi acción moral triunfe y salga adelante, aunque la realidad petrifique los resultados de mi 
acción moral haciendo desaparecer la marca de la espiritualidad que deposité en ellos (Fichte). Moral heroica, no cabe duda, tanto como para necesitar ocasionalmente el apoyo indirecto, oblicuo y como vergonzante de un «como si» ilusorio ${ }^{4}$.

El método reflexivo utilizado por Kant a la hora de establecer su intento de una fundamentación autónoma de la moral posee, como sabemos, un doble elemento explícito. Su recurso a una reflexión vertebrada en torno al quid juris?, y su desembocadura en una determinación pura, incontaminada, «geométrica»: la buena voluntad.

La pregunta referida al «derecho», en primer lugar, sólo puede desplegarse allí donde se registra algún género de enjuiciamiento por parte del hombre. No tiene ningún sentido preguntar con qué derecho percibo el mundo como lo hago o aplico estas categorías al universo y no otras. Ahora bien, con qué derecho decreto que las cosas son exactamente como las percibo y concibo, o con qué derecho juzgo mi forma (humana) de conocer como la única forma o «la mejor forma posible», éstas son preguntas perfectamente pertinentes. Y aquí es donde viene a entrar en juego la honradez: no sé si las cosas son exactamente como las percibo o concibo, no sé si Dios existe o no, no sé si tiene algún sentido un comportamiento moral por mi parte, etc., pero debo sospechar que no tengo ningún derecho a ajustar mi concepción del universo - yo incluido - a mis necesidades egocéntricas.

La «buena voluntad», por su parte, ejerce un papel de límite. Sería aquella que se ajusta perfectamente al contenido normativo del imperativo categórico. Naturalmente, su rendimiento metodológico (si cabe hablar asî) no es otro que el de representar un focus imaginarius, un «punto en el aire» cuyo papel consiste en representar una presuposición idealizante indispensable para poder juzgar la realidad en tanto que negativa, limitada, malograda, reflejando el grado de intolerable lejanía del ser con respecto a lo que debería ser.

En este sentido, las teorizaciones de Brandom y Habermas transitan en gran medida por trayectos kantianos. Su admiración por Kant no es retórica en absoluto: la única manera de escapar del actual indiferentismo moral (por no hablar de una recaída, como para compensar, en fanatismos teológicos) consiste en repensar el profundo nervus contrafáctico que anima y sostiene la reflexión kantiana sobre los límites de la razón. Razón inmanente y situada, desde luego, razón sin transcendencia, pero es de vital importancia no seguir confundiendo transcendentalidad con transcendencia ni pos-metafísico con anti-metafísico.

\section{Robert B. Brandom y el compromiso consecuencial}

La investigación filosófica del lenguaje realizada por Brandom se inspira claramente en planteamientos kantianos. Para Brandom no se trata de averiguar el grado de certeza que puede esperarse del lenguaje, sino más bien de dilucidar a qué nos obliga su utilización:

Mientras la concepción descriptiva que tiene Descartes de la intencionalidad, que se centra en la certeza, destaca como lo esencial el modo en que captamos los conceptos empleados en la cognición y la acción, la concepción normativa que tiene Kant, centrada sobre la necesidad, considera que es su dominio sobre nosotros lo que constituye el núcleo del asunto. En el centro mismo de la empresa filosófica de Kant se halla el intento de entender el origen, la naturaleza y el significado de las normas implícitas en nuestros conceptos (tanto las que rigen el empleo teórico de los conceptos en la investigación y el conocimiento como los que rigen su uso práctico al deliberar y actuar). Para Kant la cuestión más urgente es cómo entender $e l$ carácter rector de los conceptos, cómo entender su autoridad, su carácter obligatorio o su validez. Es el carácter normativo que él denomina Notwendigkeit («necesidad») $)^{5}$. 
Resulta muy interesante observar el vínculo entre el planteamiento kantiano de Brandom y su intento de establecer una lógica contrafáctica (él mismo la denomina «expresiva») capaz de «abrir» el mundo sin una referencia necesaria a los hechos pero conectándose con un mundo posible, es decir, una lógica capaz de proferir juicios sintéticos y no simplemente analíticos. El propio Brandom caracteriza su posición con el término de racionalismo lingüístico ${ }^{6}$, que se opone

[a] una comprensión del contenido en términos exclusivos del modelo de representación de los estados de cosas, [a] una comprensión de la corrección de las inferencias en términos exclusivos del modelo de validez formal, y [a] una comprensión de la racionalidad en términos exclusivos del modelo instrumental o de medios-fines ${ }^{\text {? }}$.

El resultado es una «razón elucidatoria» o expresiva que no sólo ha de presuponerse como un telón de fondo contrafáctico, sino que muy bien puede representar el fundamento real, aunque oculto, de esos tres usos del lenguaje ${ }^{8}$.

He aquí lo básico: la reflexión de Brandom, al situarse en una perspectiva débilmente contrafáctica (llamarla «idealista» sería un tanto exagerado), refleja en su interior un intento de reconstrucción pragmática del lenguaje (juego de dar y pedir razones, así como de adquirir compromisos y responsabilidades) que apunta necesariamente - pero sólo apunta- a una consideración ética (pragmáticotranscendental) del mismo, pues se apoya en dos puntos éticos cruciales como son tomarse en serio el lenguaje y salvaguardar el carácter privilegiado (y en el límite supremo) del lenguaje moral. El resultado final apunta (insistimos: sólo apunta) al hecho de que la racionalidad del individuo se fundamenta en su responsabilidad lingüística, esto es, en su capacidad de someterse libremente y hasta el final al juego de dar y pedir razones. No es casua- lidad entonces la apelación al método socrático:

El método socrático es una forma de colocar nuestras prácticas bajo un control racional, expresándolas de forma explícita, de tal modo que puedan enfrentarse a objeciones y alternativas, una forma en que puedan mostrarse como conclusiones de inferencias que sirven de justificación sobre la base de premisas aportadas como razones, y como premisas de inferencias adicionales que exploran las consecuencias de su aceptación ${ }^{9}$.

La exigencia de tomarse en serio el lenguaje permite contemplar su textura pragmático-transcendental, o sea, tanto su capacidad de exhortarnos al compromiso entre intenciones, creencias y conductas como de juzgar las disonancias o inconsistencias registradas entre estos tres elementos. Hablar no es simplemente prometer sino afirmar una oración, y

afirmar una oración consiste en adquirir implícitamente un compromiso con la corrección de la inferencia material que va desde las circunstancias a las consecuencias de su aplicación ${ }^{10}$.

El compromiso social o intersubjetivo del acto de hablar lleva a Brandom a establecer una muy certera crítica del «fiabilismo» como posición subjetiva de quien cree algo sin poder aportar razones de su creencia. Brandom pone el ejemplo de una experta en cerámica capaz de distinguir, por lo que se refiere a la cultura de la que provienen, entre diversas piezas «a ojo de buen cubero», sin aportar razones científicas, pero cuya fiabilidad es muy respetada entre sus colegas, que comprueban que «acierta» casi siempre:

¿Deberíamos considerar que nuestra experta en cerámica tiene conocimiento en vez de estar en posesión de razones, y a pesar de su desconfianza en su propia fiabilidad? En segundo lugar, ¿abonan estos ejemplos una reacomodación de la epistemología centrándola en la fiabilidad de los procesos de formación de las creencias, en lugar de en la posesión de razones? En tercer lugar, ¿la posibilidad y la conve- 
niencia de esa reacomodación de la epistemología significa que la función explicativa desempeñada por los conceptos de razones, datos, inferencias y justificaciones puede ser sustituida por los procesos fiables de formación de creencias? Existe la tentación de trasladar, de una respuesta afirmativa a la primera pregunta, una respuesta afirmativa a las otras dos. Yo sostengo que hay que resistir a esa tentación "I.

La crítica al fiabilismo, que ha de ser entendida (aunque con ciertas reservas) dentro de una crítica más general al irracionalismo, en el sentido, por ejemplo, del indiferentismo ontológico del lenguaje defendido por Richard Rorty, se mantiene en un campo epistemológico empirista (al fin $\mathrm{y}$ al cabo la experta en cerámica del ejemplo se apresura a buscar datos confirmadores de su «corazonada»), lo cual, si recordamos el rechazo brandomiano a lo que él mismo denomina «lógica representacionista», es decir, a una lógica atada a los hechos empíricos, parece implicar una contradicción, a no ser que elevemos la mirada hacia el horizonte al que apunta la intención de Brandom: la fiabilidadsin-razones no es sostenible tampoco en el marco de una lógica contrafáctica, aunque por razones diferentes. En el plano empírico basta con comprobar si la «corazonada» estaba o no en lo cierto, mientras que en los planos epistemológico (en el que también hacen su aparición determinados valores) y, sobre todo, moral - no tratado explícitamente por Brandom, pero reconstruible a partir de sus premisas-, la «corazonada» fiabilista viene a quedar refutada por su propia estructura interna de discurso sin razones ni compromisos intersubjetivos. En el terreno de los hechos el fiabilismo simplemente puede acertar. En el de los valores, en cambio, constituye un discurso ilegítimo en su misma raíz [reproche que, aunque acierte en los hechos, también puede serle imputado en tanto que discurso (pseudo)científico] ${ }^{12}$.

El establecimiento de una lógica material (semántica), por oposición a la me- ramente formal, y contrafáctica, por oposición a una lógica empirista, atada a los hechos, constituye el umbral indispensable para la reconstrucción de un discurso moral no sólo como vocabulario especializado o «privilegiado» en la terminología de Brandom (cosa que niegan los humeanos radicales), sino incluso como vocabulario supremo o regidor del resto de vocabularios, como discurso de discursos. Este segundo paso se encuentra implícito en la reflexión de Brandom.

La crítica humeana radical a la ética en tanto que discurso diferenciado se basa en la reducción de cualquier afirmación determinada por un «debe» 0 «no debe» a una mera apariencia detrás de la cual se agazapa un discurso fáctico gobernado por deseos y preferencias subjetivas. O el «debo» es un «prefiero» - viene a decir Humeo no es más que un vocablo retórico y vacío. Brandom escribe a este respecto:

La tradición empirista trata de retrotraer el discurso acerca de las razones para la acción, así como las normas que la rigen, a las preferencias y deseos subyacentes, que se conciben al mismo tiempo como motivos intrínsecos y como la única clase de cosas que pueden constituir motivos intrínsecos [cursiva nuestra]. Por lo tanto, cualquier expresión completa de una razón para la acción ha de incluir una especificación de qué es lo que quiere el agente, en virtud de lo cual funciona (en el plano motivacional) esa razón como la razón para ese agente. En lo que aquí se cuenta, y en contraste con los instrumentalistas, las preferencias y los deseos se explican en términos de compromisos con ciertas pautas de inferencia práctica, es decir, en función de qué es una razón para qué y no a la inversa ${ }^{13}$.

La reconstrucción brandomiana del discurso moral como vocabulario diferenciado (con sus rasgos bien definidos, con su característica lógica interna) no sigue, como sabemos, un camino semántico - al menos no en un primer momento - , sino un camino pragmático $\mathrm{o}$, más exactamen- 
te, pragmático-transcendental, pues intervienen de un modo decisivo las nociones de compromiso y de responsabilidad. Se trata no tanto de entender qué significa «yo debo hacer esto o lo otro», cuanto de captar a qué me obliga tal afirmación. Para tal reconstrucción viene a servirse Brandom del desarrollo de tres elementos constitutivos del discurso moral: (I) la noción de «inferencia material», (II) la noción de «vocabulario privilegiado» $\mathrm{y}$, por último, (III) la noción de «compromiso consecuencial».

(I) La inferencia material refleja la conexión deductiva entre premisas y conclusiones (dicho en lenguaje pragmatista, entre intenciones y creencias, por un lado, y conductas, por otro) teniendo muy en cuenta el contenido semántico de los elementos integrantes en la inferencia. De manera muy parecida a como ocurre en el lenguaje matemático y el problema de su vacío semántico ${ }^{14}$, el lenguaje lógico formal no permite la adopción de compromisos semánticos ni pragmáticos, sino sólo formales, gobernados exclusivamente por el principio de no-contradicción. Si se parte, por ejemplo, de la formulación «si $p$ entonces $q »$, lo único a lo que se compromete quien ha proferido tal formulación es a poner $q$ si ha puesto $p$ y a quitar $p$ si ha quitado $q$. Nada más ${ }^{15}$. Pero esto resulta excesivamente pobre desde un punto de vista semántico y pragmático:

Considérese la inferencia «si Pittsburg está al oeste de Princeton entonces Princeton está al este de Pittsburg» y «si ahora se ha visto el rayo entonces pronto sonará el trueno». Son los contenidos de los conceptos oeste y este los que hacen del primer ejemplo una buena inferencia, y los contenidos de rayo y trueno, así como los conceptos temporales, los que hacen correcta a la segunda. El respaldo a esas inferencias constituye parte de la captación de esos conceptos independientemente de cualquier competencia lógica ${ }^{16}$.
La verdad es que el ejemplo resulta demasiado ambiguo, pues que una ciudad se encuentre al este $o$ al oeste de otra no deja de ser un hecho convencional, así como que tras el rayo venga el trueno no deja de ser un hecho habitual. Si son los contenidos de los conceptos los encargados de suministrar la corrección deductiva de una inferencia material, tenemos dos problemas. Uno, que estamos haciendo descansar una versión pragmática de la lógica en su versión semántica y, dos, que estamos reduciendo las posibilidades contrafácticas de una lógica material - cuyo establecimiento se nos prometía - a la estructura fáctica de una lógica atada a los hechos empíricos. En este sentido, no termina de verse muy bien de dónde extrae la lógica material su fuerza de convicción, si de los elementos empíricos o del encadenamiento reflejado en las conectivas «al este», «al oeste», «primero», «luego». Parece que de los primeros. Pero entonces las posibilidades de una lógica material y contrafáctica se tornan enormemente problemáticas. Considérese el siguiente ejemplo. Supongamos que yo afirmo esto: «si todos los seres humanos somos iguales (en tanto que se nos debe considerar humanos) y si el ser humano tiene derecho a la alimentación, entonces todos tenemos derecho a la alimentación». La pregunta es si la perspectiva ofrecida por Brandom en su ejemplo resulta suficiente para salvaguardar la corrección de esta inferencia (que cumple las condiciones de ser una inferencia material y contrafáctica). Que Pittsburg y Princeton existen y que están situadas de cierta manera en el mapa, así como que tras el rayo suele venir el trueno - Hume dijo algunas cosas al respecto- constituyen dos inferencias correctas porque sus cuatro elementos empíricos son evidentes. Mas si yo afirmara, por ejemplo, que Alfalandia está al norte de Betalandia y que por tanto Betalandia está al sur de Alfalandia, entonces nos quedamos a oscuras, pues no conocemos la 
existencia de tales países. La inferencia es formalmente correcta, pero ni semántica ni pragmáticamente tenemos la menor idea de cómo entender o qué hacer con esa información. El ejemplo ético de la alimentación se aproxima a este segundo caso, pues desde una perspectiva empirista no es evidente ni que seamos iguales ni que el ser humano tenga derecho a la alimentación ${ }^{17}$. La indudable fuerza pragmática (y pragmático-transcendental) de estos elementos ha de provenir de otro sitio, ha de instalarse en otra perspectiva. Más adelante volveremos sobre esta cuestión.

(II) Un vocabulario privilegiado representa un conjunto coherente de elementos semánticamente articulados, algo así como una "gran familia de significados». Cuando alguien se introduce de una manera comprometida y responsable en un vocabulario privilegiado (por ejemplo, en el lenguaje de la metalurgia) sabe de qué está hablando:

Aquí no se presenta la comprensión o la captación de un contenido proposicional como si se encendiera una luz cartesiana, sino como el dominio práctico de una cierta clase de acción inferencialmente articulada, como una respuesta diferenciada y acorde a las circunstancias de una utilización correcta de un concepto, que además distingue las consecuencias inferencialmente correctas de estas aplicaciones. No es una cuestión de todo o nada. El metalúrgico entiende el concepto telurio mejor que yo, pues el adiestramiento le ha hecho dominar los vericuetos inferenciales de su empleo de una forma que yo sólo puedo imitar muy toscamente. En esta explicación inferencialista, pensar de forma clara es una cuestión de saber a qué se está comprometiendo uno con una afirmación y qué habilita a uno para ese compromiso [cursiva nuestra]. Escribir claramente es proporcionar suficientes pistas a un lector para que pueda inferir con qué pretende uno comprometerse con cada afirmación, y qué es lo que uno considera que le habilitaría para ese compromiso. Si no se captan esos componentes no se capta tampoco el compromiso inferencial que entraña el uso del concepto, con lo que deja de captarse su contenido conceptual ${ }^{18}$.

En este sentido, cualquier vocabulario viene a representar una región semántica que gobierna su propio espacio, obligando, permitiendo o prohibiendo determinadas afirmaciones. El problema del ejemplo aducido por Brandom vuelve a ser que, al ser un elemento empírico, el telurio no permite al experto en metalurgia afirmar cualquier cosa de él precisamente por la fuerza de la experiencia que le respalda a la vez que le obliga. La piedra de toque de la fuerza inferencial que respalda a nuestro metalúrgico es la comprobación. Mas ¿qué tipo de comprobación podemos esperar de una lógica contrafáctica, y más específicamente, de un discurso moral?

Brandom establece algo así como una cabeza de puente con objeto de ganar posiciones antes de plantear una línea de defensa de la posibilidad de un vocabulario así. Insiste en que cualquier vocabulario privilegiado gobierna su propio espacio:

Si lo que interesa es la forma lógica, entonces hay que ser capaz de distinguir previamente un cierto vocabulario como peculiarmente lógico. Una vez hecho esto, la estrategia semántica fregeana de buscar aspectos inferenciales que son invariantes con la sustitución permite obtener una noción de inferencias lógicamente válidas. Pero si se escoge el vocabulario teológico (o estético) como el principal, entonces examinar qué sustituciones de vocabulario no teológico (o no estético) por vocabulario no teológico (o no estético) preservan la corrección de la inferencia discriminará las inferencias que son buenas en virtud de su forma teológica (o estética). De acuerdo con esta concepción, la bondad formal de las inferencias se deriva y se explica en términos de la bondad material de las inferencias, por lo que no debería acudirse a aquélla para explicar ésta ${ }^{19}$.

Parece claro entonces que si existe un vocabulario teológico o estético (regidos por valores, es decir, contrafácticos) no hay razón para suponer que no existe un 
vocabulario moral dotado, al igual que aquéllos, de límites definidos, de estructura lógica y, sobre todo, de capacidad para demandar compromisos y responsabilidades inferenciales y pragmáticas (en el caso del vocabulario moral, pragmáticotranscendentales). También éste gobierna y defiende su propio espacio. Tampoco es posible aquí afirmar cualquier cosa o torcer a capricho la dirección correcta de las argumentaciones o cancelar y detener el proceso de razonamiento. Si hablar es tomarse el lenguaje en serio, el vocabulario moral es, en principio, tan sólido y digno como el que más. El problema es que tal género de vocabulario, al representar además un papel de meta-vocabulario, (pues todo discurso, sea empírico o contrafáctico, demanda compromiso y responsabilidad, es decir, honradez, por parte de quien lo está utilizando, y éstas son precisamente las determinaciones del vocabulario moral), aspira - con toda razón- a elevarse hasta la cúspide de todos los razonamientos posibles. Ya es mucho salvaguardar un estatuto sustantivo al lenguaje moral frente a los humeanos radicales (Rorty), pero ¿se puede esperar la supremacía de dicho lenguaje?

Si hay algo que caracteriza el espíritu de los tiempos (por emplear la clásica fórmula de Hegel) es la asunción inmediata y acrítica - en una palabra, la creencia - de que la ética constituye, todo lo más, un lenguaje entre lenguajes sin ningún género de privilegio cognitivo o pragmático. En un libro reciente ${ }^{20}$ expresa Javier Echeverría este punto de vista (denominado por él «axiología de la ciencia» por oposición a una ética de la ciencia) mediante una argumentación desplegada en tres pasos. Un primer paso metodológico:

Nuestra axiología no afirma la existencia de un sistema general de valores que defina la ciencia ideal, y por ello no proponemos ningún ideal normativo para regular en última instancia la actividad científica ${ }^{21}$
Renunciando de esta manera a cualquier género de jerarquización de lenguajes y, por lo tanto, a la entronización de un ideal regulativo, el enjuiciamiento de la actividad científica debe remitirse, en el marco de una teorización hecha a la medida de la sociedad liberal, a la armonización de la pluralidad fáctica de la realidad social (donde, como suele ser habitual, la pluralidad de intereses se acoge a la cobertura de una pluralidad de opiniones):

Como criterio general diremos que será mejor aquella actividad científica que muestre mayor capacidad para integrar diversos sistemas de valores, a veces opuestos y en conflicto, de modo que la satisfacción de todos y cada uno de ellos sea exigible, aunque sea en un cierto grado ${ }^{22}$;

con lo que se sigue, como corolario, el hecho de que

no se puede seguir manteniendo que la ética y la moral ofrecen un marco adecuado para reflexionar sobre los valores de la ciencia y la tecnología. Tienen su importancia, sin duda, pero el análisis axiológico de la actividad científica no puede limitarse a las cuestiones morales. Precisamente por ello hay que desarrollar una axiología de la ciencia, no simplemente una ética de la ciencia. De lo contrario estaremos ignorando buena parte de los problemas axiológicos más importantes suscitados por la ciencia contemporánea ${ }^{23}$.

Naturalmente, cabe hablar aquí de una subyacente intención pragmática del autor, que no es otra que respetar, por medio de una decisión dogmática, la realidad social del capitalismo ${ }^{24}$, algo que impide de raíz la constitución de un discurso moral capaz de cuestionar la propia posición del autor al respecto. El planteamiento pluralista se autoinmuniza ante cualquier virus contrafáctico.

La posición de Brandom es bastante más compleja. Sin comprometerse explícitamente a favor del establecimiento de un discurso moral como vocabulario supre- 
mo, su reflexión señala críticamente los límites éticos de cualquier vocabulario, introduciendo, desde «dentro», la obligación de dar y pedir razones en tanto que justificaciones:

Las prácticas inferenciales materiales, que rigen y hacen posible el juego de dar y pedir razones, entran en el juego y, por tanto, en la consciencia, como cuestiones explícitas objeto de discusión y justificación ${ }^{25}$.

Y, desde «fuera», colocando en cada vocabulario o uso del lenguaje (por ejemplo, el uso de un lenguaje racista) una especie de «rejilla» encargada de permitir o prohibir determinados elementos en función de su admisibilidad o defendibilidad morales:

Al evaluar la introducción y la evolución de un concepto, lo que hay que preguntarse propiamente no es si ya se ha respaldado una inferencia entrañada de forma que no haya ningún contenido nuevo entrañado, sino si esa inferencia debería ser respaldada. El problema con [términos como] «boche» o «negro» ${ }^{26}$ no se produce cuando nos encontramos explícitamente con el compromiso inferencial material que da al término su contenido y que resulta ser nuevo, sino cuando se puede advertir que es indefendible e inapropiado, un compromiso que no estamos dispuestos a asumir [cursiva nuestra] ${ }^{27}$.

No hay dificultad en traducir ese «no estar dispuestos a asumir» a no creerse con derecho a asumir, pues ésta es la verdadera condición de posibilidad de aquélla. Por lo demás, y por seguir con el ejemplo de Brandom, la afirmación iya está aqui otra vez ese negro! nos empuja a una cohesión interna (pues supone que no es la primera vez que hemos visto a ese individuo, con lo que afirmaciones como es la primera vez que lo veo se hallan vetadas) y a una coherencia «externa», puesto que al proferir asi esa frase estamos «arrastrando», lo queramos o no, seamos conscientes de ello o no, una doble connotación, la de preferir «negro» a «ese individuo», y la de utilizar, como pieza sub-textual encargada de establecer connotaciones extralingüísticas, un indisimulado tono de impaciencia o fastidio. Pues bien, al defender la doble rejilla interna y externa, la reflexión de Brandom parece apostar por la posibilidad de un vocabulario moral a la vez privilegiado y supremo que, en última instancia, asuma el gobierno general de todo el lenguaje $y$, por lo tanto, de todos los usos del lenguaje.

(III) El resultado de todo esto no puede ser más interesante, pues viene a enfrentarse cara a cara con una confusión (que hace verdaderos estragos en unos tiempos tan relativistas y «plurales» como los nuestros) entre sinceridad y honradez, confusión que intenta precisamente utilizar para su provecho el tercer elemento apuntado por Brandom a la hora de establecer un discurso moral como vocabulario supremo, a saber, la capital noción de compromiso consecuencial. Supongamos que un racista nos dice que cree que los negros no son humanos, que su intención es perjudicarles todo lo que esté en su mano, y que siempre que puede actúa en consecuencia. Desde un punto de vista intuitivo podemos captar que este racista es sincero, pero no honrado. Si la sinceridad es un estado de coherencia entre lo que se piensa, se dice y se hace, la honradez es un estado de coherencia muchísimo más complejo entre lo que se piensa/se dice/se hace y lo que se debe pensar/decir/ hacer ${ }^{28}$. En este sentido, el problema radica en si el alcance de la noción brandomiana de compromiso consecuencial se limita a la esfera de la sinceridad o se extiende hasta la de la honradez. Brandom sostiene, olvidando la presencia de una rejilla «exterior», que el compromiso consecuencial supone la presencia de una doble obligatoriedad interna, a saber: que los motivos de una acción (pensar/decir/ hacer) sean verdaderas razones y que tales razones sean las auténticas causas de 
dicha acción ${ }^{29}$. Lo segundo no tiene, en este contexto, tantos problemas como lo primero. ¿Qué se entiende aquí por una verdadera razón? Si entendemos que se trata de una argumentación que ha de ser puesta al servicio de un juego intersubjetivo de dar y pedir razones (lo que supone que las famosas «corazonadas» del fiabilismo no pueden constituir razones), aún falta por aclarar si este juego se sostiene por sí mismo (en el marco de un consenso fáctico donde el racista ofrece razones que convencen al resto de racistas o de incau tos) o si debe someterse al juego superior de dar y pedir razones honradas ${ }^{30}$. Está bastante claro, a juzgar por la afirmación de Brandom de la inadmisibilidad de la utilización connotada de «boche»o «negro», que se trata de lo segundo. Pero el problema se manifiesta en el hecho de que la defensa del discurso moral como vocabulario supremo no supera los límites impuestos por lo primero, con lo que el simple dar y pedir razones en general, que es el fundamento de la sinceridad, funciona como si fuera el fundamento de la honradez. En este sentido precisamente el laxo recurso brandomiano al concepto de ley en Kant no parece ser capaz de romper la subrepticia sustitución de la honradez por la mera sinceridad:

Modelar la acción a partir de la percepción [término con el que Brandom denota los inputs del sujeto como intenciones, creencias, etc.] hace honor al hecho crucial de que el reconocimiento de los compromisos puede causar y ser causado. Kant define la voluntad racional como la capacidad de derivar actuaciones a partir de la concepción de leyes. Sugiero que podemos cambiar «la concepción de una ley» en esa fórmula por «el reconocimiento de un compromiso». La ley es el término kantiano para una regla que obliga - una norma-. La concepción que uno tiene de una ley es la de aquello a lo que está obligado. Por tanto, la posesión de una voluntad racional puede concebirse como la posesión de la capacidad de responder fiablemente al reconocimiento de ese compro- miso, produciendo actuaciones diferenciadas que se corresponden con el contenido del compromiso adquirido ${ }^{31}$.

Verdaderamente, la única manera de conectar los planteamientos de Kant y de Brandom en este sentido parece consistir en regresar a la definición kantiana de «ley». Una ley es un imperativo universal basado en la intuición del derecho moral que tiene alguien a hacer algo, no simplemente algo a lo que está obligado (que sería el efecto de la ley, no su «esencia»). Si el racista de nuestro ejemplo odia a los negros, se encuentra «obligado» (por la presión ejercida por sus propios correligionarios) a actuar conforme a esa «ley» (Kant diría «máxima») y no permitir, por ejemplo, que su hija se case con un negro. Hasta ahí se trata de una obligatoriedad por sinceridad. Mas una obligatoriedad por honradez como único fundamento de una voluntad racional (lo que supone que la honradez no consiste simplemente en dar un paso más y pasar de ser sincero a ser muy sincero, sino en transformar los criterios de formación de creencias) comienza obligando al racista a preguntarse con qué derecho odia a los negros (pregunta esta que, dicho sea en honor a la verdad, le trae completamente sin cuidado). En este sentido, el juego de dar y pedir razones necesita de algún género de reconstrucción pragmático-transcendental que haga fijar nuestra atención en lo que debe pensar/decir/hacer el sujeto dados un compromiso y una responsabilidad que apuntan necesariamente más allá de aquella lógica material que, por no haberse arriesgado a proponer ejemplos no empíricos, hace descansar la racionalidad de la voluntad en una condición necesaria pero no suficiente, como es la de mantener abierto el canal del lenguaje intersubjetivo a la hora de explicar y justificar acciones. Ya incluso el propio término justificar parece apuntar a un plano pragmático-transcendental de acciones considerables como justas, esto es, más allá de una 
consideración simplemente pragmática (a qué me obliga la afirmación «debo hacer algo» sin distinguir los diferentes planos del verbo «deber»):

Respaldar una inferencia práctica como preservadora de una habilitación equivale a considerar que las premisas doxásticas [corporeizadas en opiniones] proporcionan buenas razones para la conclusión práctica. Mostrar que una pieza de buen razonamiento práctico es una conclusión con una cierta intención equivale a mostrar esa intención y la acción que desencadena - si es que la hay - como una acción razonable a la luz de los compromisos que las premisas muestran. Por tanto, todos los «debe» que hacen explícitas las especies de razonamientos prácticos que aquí se aducen como ejemplos, el «debe» prudencial, el «debe» institucional y el «debe» incondicional, son clases diferentes de «debes» racionales [...] Recuérdese que la habilitación ofrecida por las razones institucionales o prudenciales no necesita ser respaldada por el atribuyente. Como pone de relieve Davidson, no es preciso que consideremos que las razones del agente son buenas razones ${ }^{32}$.

Toda la fuerza interior de la reflexión de Brandom en torno a la lógica material y contrafáctica proviene de su implícita convicción central, a saber, que el lenguaje posee una indiscutible fuerza a la hora de generar creencias y promover conductas. Ahora bien, si el asunto gira en torno al hecho de actuar por razones y no sólo con ellas, ello se debe, sin duda alguna, a la existencia de una cierta verticalidad ontológica, a una especie de «tercera dimensión» en el propio lenguaje que posibilita un proceso de profundización semántica desarrollada a base de implicaciones no advertidas (tesis esta radicalmente enfrentada al indiferentismo ontológico del lenguaje de Rorty, por ejemplo). Con esto quiere decirse que quien se compromete a tomarse el lenguaje verdaderamente en serio no ha de temer arriesgarse a profundizar y «dejarse llevar» por él, a condición - eso sí- de que en última instancia haga girar sus acciones lingüísticas, y por ende sus acciones morales, en torno a la pregunta pragmático-transcendental por excelencia: ¿con qué derecho afirmo $(y$, por tanto, me comprometo a realizar) esto o aquello?

Pero cabe preguntar, a su vez, de dónde extrae esta pregunta la fuerza normativa que le confiere el papel de clave de bóveda de un discurso moral elevado al rango de vocabulario supremo. El racista que desprecia a los individuos de raza negra podría ofrecer razones de sus creencias invocando a su propio interés $\mathrm{o}$ al hecho de haberlas recibido del pasado familiar o social en que creció, y eso en el mejor de los casos. Lo más frecuente será que invoque toda una serie de prejuicios antropológicos y aun teológicos ( Dios creó a los negros...») alimentados con retazos empíricos y observaciones sesgadas, tales como el pequeño número de individuos de raza negra que han llegado a presidentes de gobiernos democráticos o la escasa relevancia filosófica o científica alcanzada por dicho género de individuos. Naturalmente, éstos son hechos constituidos por valores (el negro es inferior, luego no tiene derecho a la educación ni a la igualdad de oportunidades), lo que, al fin y a la postre, supone la presencia en la conciencia empírica del racista de un doble prejuicio: el prejuicio antropológico contra los negros y el prejuicio epistemológico de considerar que los hechos empíricos registrados en el estrecho escenario de su biografía son, a la vez, neutrales e irrebasables (¿para qué habría de preguntarse él con qué derecho piensa como piensa de los individuos de raza negra?, ¿acaso habría que preguntar también con qué derecho digerimos como lo hacemos?).

Acabamos de señalar el doble prejuicio antropológico y epistemológico. En ambos casos se da un factor común, la irrebasabilidad de una perspectiva egocéntrica. El desprecio a razas distintas pone en marcha el prejuicio - de naturaleza 
moral - contra lo diferente a ego. El atenerse a los hechos como tales, el prejuicio de ego como observador privilegiado (¿qué me está usted intentando decir?, ¡lo estoy viendo con mis propios ojos!). Se entiende entonces que la descentración, tanto epistémica como moral, constituye el «núcleo duro» de una actitud moral exigible a todo ser racional en el sentido de un proceso de maduración que excluya la posibilidad de provocar daño o hacer sufrir a otros seres vivos (y aquí el conjunto de seres vivos absolutamente respetables varía en función del grado de descentración conseguido). Mas con esto llegamos a una vieja y dolorosa paradoja. La descentración epistémica ha resultado siempre incomparablemente más sencilla que la descentración moral (al margen de situaciones en que se registran intentos de refutar el darwinismo en nombre de la posición del hombre según algún texto sagrado). Tal cosa se debe, probablemente, al hecho de que el interés egocéntrico está menos dispuesto a someterse a una superación práctica que a someterse a una superación teórica por el carácter «lejano» y aparentemente menos problemático de ésta: al fin y al cabo resulta «razonable» (en el sentido de comprensible) la aseveración de Lucy, la estirada amiga de Charlie Brown: I love humanity; it's the people what I hate («yo amo a la humanidad; lo que me revienta es la gente»). Pero, sea como sea, Brandom concibe el proceso de moralización a la manera kantiana, como un acercamiento problemático (y en ocasiones doloroso) al sujeto transcendental que todos «llevamos dentro». En la teoría, asumiendo las concepciones teóricas suministradas por los conocimientos científi$\cos y$, en la práctica, ajustando nuestras conductas al discurso moral como vocabulario supremo (en Kant, incondicionado). En este doble sentido, el «creo» ha de ser sustituido por un «sé», y el «deseo», por un «debo». El yo empírico, histórico, ha de - tiene la obligación moral de - ele- varse hasta la perspectiva universal de una tercera persona y autoobligarse desde ahí a un conocimiento y una conducta incrustados en un marco en el que he de conocer lo que se debe conocer $y$ he de actuar como se debe actuar:

Lo que expresa el «debe» normativo se relaciona con el «haré» intencional como el uso de la tercera persona con la primera, es decir, como la atribución de compromisos prácticos (a otros) con el reconocimiento de compromisos prácticos (de uno mismo). El uso del vocabulario normativo, como «debe», expresa la atribución a un agente de un compromiso con una pauta de razonamiento práctico, mientras que el uso de «haré» expresa el reconocimiento que hace el agente de la clase de compromiso práctico que puede aparecer como la conclusión de ese razonamiento práctico. Son esos reconocimientos los que, en agentes competentes, se sintonizan para la producción de las correspondientes actuaciones bajo las condiciones favorables. Esta relación proporciona una forma de hacer inteligible la debilidad de la voluntad (akrasia), porque ese fenómeno se da cuando la auto-atribución de compromisos prácticos (que se hacen explícitos mediante la forma yo debería) no tiene la significación causal del reconocimiento de los compromisos prácticos (explícitos mediante la forma yo haré) ${ }^{33}$.

La constatación de que no siempre actuamos como debiéramos (lo que tampoco constituye para Brandom ningún misterio indescifrable) viene a poner de manifiesto, como acabamos de ver, el hecho de que es la debilidad de la voluntad, y no la irrebasabilidad de la subjetividad o del auto-engaño (o sea, razones «teóricas»), la responsable del incumplimiento del deber, es decir, de la contradicción pragmática entre «debería hacer esto o lo otro» y «no tengo la menor intención de hacerlo». El carácter cognitivo (racional) del vocabulario moral excluye la posibilidad de endosar las contradicciones pragmáticas (o «performativas») a no se sabe qué borrosidad conceptual a la hora de establecer ante la conciencia el conteni- 
do normativo del deber. Por decirlo de un modo breve y coloquial: si usted no cumple su deber es porque no le da la gana, no porque no lo conoce ${ }^{34}$. No es un asunto de imposibilidad teórica, sino de decisión (en todo caso qué debo hacer es cuestión que compete a la teoría, mientras que debo hacer compete a la voluntad). En este mismo sentido, ya desde Kant (en realidad, desde Platón) se abre aquí una problemática horquilla entre los problemas de la fundamentación de la moral (dónde encontrar, dónde fundamentar la noción de deber) y los de la motivación en el obrar moral (por qué he de comprometerme moralmente). Al margen ahora de que, proyectados según su propia lógica interna, ambos planos resultan ser incompatibles, el asunto reside en que la relación entre cognición moral («sé que debo») y volición moral («quiero hacer lo que debo») está muy lejos de ser una relación inmediata y transparente. Más bien viene a representar una especie de «enzarzamiento en el aire» donde uno y otro elemento se implican y se limitan mutuamente. Consideremos, a título de ejemplo, las siguientes afirmaciones en que se despliega el enzarzamiento aludido:

(1) «Usted debe hacer esto».

(2) «Usted debe querer hacer esto».

La afirmación (2) refleja la sumisión teórica de la voluntad del agente al deber consignado en (1), pero el resultado es ambiguo, pues querer es un acto libérrimo que no acepta imperativos. Para solucionar este dilema, dos derivaciones:

(3) «Lo quiera o no, usted debe hacer esto».

Derivación asimilable semántica pero no formalmente a (1) y que, al reflejar una coacción que debe provenir del exterior - pensemos, por ejemplo, en un lenguaje jurídico-, es incomparablemente más realista que:
(4) «Si quiere usted ser racional, debe querer hacer esto».

Derivación que, al depender de si quiero o no quiero considerarme racional, viene a reproducir el problema de (2) («usted debe querer ser racional, por tanto, etc.»). Una última derivación nos traslada al sancta sanctorum del discurso moral como vocabulario supremo:

(5) «Usted no puede no querer ser racional».

Donde la sustitución del «usted no debe» por el «usted no puede» se configura con la intención de colocar el asunto en un marco lógico e incluso ontológico donde, al final, acabamos arribando a una supuesta imposibilidad lógica ( $\ll$ si usted afirma no querer ser racional está usted afirmando algo, por tanto, está usted contradiciéndose») u ontológica («si usted afirma no querer ser racional está usted suicidándose como ser racional»). En otro lugar tuvimos ocasión de tratar esto con el detalle que merece ${ }^{35}$. Aquí basta con señalar que la imposibilidad de solventar esta ardua cuestión («quien no quiere, simplemente, no quiere», por utilizar la expresiva formulación de Tugendhat) viene a situarnos en los límites últimos de la eficacia pragmática del lenguaje. Brandom es perfectamente consciente del problema, y la verdad es que hace lo único que puede hacer dadas las restricciones del marco en que despliega su teorización, limitarse a señalar la necesidad objetiva de unas reglas del juego y sugerir una muy razonable noción de lealtad por parte de los jugadores:

$\mathrm{Si}$ alguien afirma «el reloj es rojo», debe añadir también «el reloj tiene color». Hacer la primera jugada le obliga también a estar dispuesto a hacer la segunda. Esto no quiere decir que todos los jugadores tengan realmente la disposición que deben tener. Puede que alguien no actúe tal como está comprometido u obligado a actuar, puede romper o no seguir ese tipo de regla del juego, al menos en determinados 
casos, sin que por ello sea expulsado del grupo de jugadores del juego de las afirmaciones. No obstante, mantengo que los juegos afirmativos deben tener reglas de este tipo: reglas de compromiso consecuencial.

¿Por qué? Pues porque para que una jugada sea reconocible como afirmativa no debe ser vana, debe suponer una diferencia, debe tener consecuencias con respecto a lo que es apropiado hacer según las reglas del juego. Las afirmaciones expresan juicios o creencias. Poner una oración en la lista de juicios, ponerla en una caja de creencias, tiene consecuencias en cómo se debe actuar, juzgar y creer racionalmente. Puede que seamos capaces de construir casos en los que sea inteligible atribuir creencias que carezcan de consecuencias y estén aisladas de sus compañeras. «Creo exactamente que las vacas son bobas, eso es todo. De eso no se sigue nada y no estoy obligado a actuar de ninguna manera concreta basándome en esta creen cia». Puede ser, pero no todas nuestras creencias pueden entenderse racionalmente de ese $\operatorname{modo}^{36}$.

Naturalmente, la lealtad, el querer jugar el juego, no es una cuestión cognitiva (en contraposición al sentido socrático de que quien no quiere ajustar su conducta a un compromiso racional es que no ha llegado a entender, a ver, su necesidad). «Sé que debo ser leal en el juego, pero el caso es que no me da la ganas dice o piensa necesariamente el free rider de nuestro ejemplo. Tal saber (plano cognitivo) no le compromete para su actuar (plano volitivo), y eso es precisamente lo que sume en la perplejidad a Brandom -y a cualquiera-. Los argumentos de éste, sin embargo, no pueden sino limitarse a incidir en la autopercepción del sujeto desleal ( «ino se le cae a usted la cara de vergüenza?»).

La duplicidad brandomiana entre compromiso (commitment) y habilitación (entitlement) no parece ser de gran ayuda aquí, pues, al consabido recurso a ejemplos empíricos no demasiado comprometedores desde un punto de vista moral, viene a añadirse una aparente redundancia (pues comprometerse con una afirmación y estar habilitado para proferirla no se distinguen demasiado en un plano pragmático, al menos tal y como nos lo presenta Brandom), que sólo puede empezar a deshacerse si la expresión «buenas razones» (que es la que emplea Brandom) se asimila a un modelo pragmático-transcendental transformándose en la pregunta con qué derecho. Por ejemplo, no parece tener demasiado sentido afirmar «estoy habilitado para (= tengo derecho a) afirmar que el reloj es rojo», pero sí lo tiene afirmar «no estoy habilitado para (= no tengo derecho a) afirmar que los seres humanos no somos iguales o no tenemos los mismos derechos de alimentación, salud, educación, etc.».

No obstante, pese a la re-traducción propuesta del término «habilitación», la verdad es que el problema de la motivación no parece resolverse por ese lado. Puede decirse que

hacer una afirmación es adoptar un tipo concreto de postura normativa con respecto al contenido inferencialmente articulado. Es aceptarlo, asumir su responsabilidad, comprometerse con ello. La diferencia entre tratar algo como una afirmación o tratarlo solamente como un grito inarticulado, entre considerar que es una jugada del juego de las afirmaciones y considerar que es una acción insustancial, está simplemente en si uno considera que se acepta un compromiso que está articulado de manera apropiada mediante sus relaciones consecuenciales con otros compromisos. Ésas son relaciones racionales por las que aceptar un compromiso obliga racionalmente a aceptar otros relacionados con él como consecuencias inferenciales ${ }^{37}$.

Puede decirse esto, en efecto, y puede concluirse que el incoherente moral no sólo no es racional, sino que ni siquiera actúa como un ser humano al sustituir el juego del lenguaje por un parloteo ininteligible o pseudo-coherente (retórico), mas este tipo de elementos teóricos no parecen hacer mella en su interior. El problema de Brandom es el problema de Kant. Tener que suponer unos elementos contrafácticos 
(al menos no empíricos en el sentido usual del término) como «honradez», «conciencia», etc., con la esperanza de motivar a los jugadores a que jueguen el juego del vocabulario moral. El rechazo por parte de Brandom de todo lo que connote satisfacción, provecho o recompensa reviste un mérito enorme, desde luego, alejándole de todo aquel género de utilitarismos que gobiernan los dilemas del prisionero, las teorías de juegos de optimización, etc., sólo que al precio de fundamentar de un modo simplemente contingente la necesidad del hombre de comportarse como un ser racional. Como hemos estado viendo, los límites de tal contingencia coinciden con, o mejor, reflejan, los límites de la capacidad de motivación del lenguaje.

\section{Jïrgen Habermas y los presupuestos idealizantes}

Al igual que Brandom reconoce el fuerte talante kantiano de su propia noción de «inferencia contrafáctica» como el punto nodal a partir del cual se desarrolla el compromiso consecuencial entre los hablantes, también Jürgen Habermas señala el camino que une su proposición de «presupuestos idealizantes» al talante normativo, contrafáctico, del pensamiento de Kant:

Si no me equivoco, la transformación de las «ideas» de la razón pura de Kant en presuposiciones idealizantes de la acción comunicativa permite encarar todas las dificultades en relación con el papel fáctico que, en un plano performativo, juegan los supuestos contrafácticos ${ }^{38}$.

De hecho, la reivindicación habermasiana de Kant se extiende hasta el punto de reconocer no sólo que la filosofía analítica no ha comprendido correctamente las consecuencias de que la aplicación del giro lingüístico a la reflexión transcendental kantiana necesita conservar su fuerza contrafáctica ${ }^{39}$, sino también que la deuda del pensamiento analítico actual (Sellars,
Dummet, Brandom) con Kant es mucho más sólida de lo que suelen reconocer estos autores ${ }^{40}$.

El acceso reflexivo habermasiano a la realidad social concebida como contexto en el que se desenvuelven todos los procesos lingüísticos conformadores de la conciencia ha de partir necesariamente (es decir, si quiere precisamente esquivar todos los inconvenientes de un contextualismo absoluto) de un plano ideal como focus imaginarius que funciona como punto de referencia crítico capaz de señalar la profunda negatividad moral (pragmático-transcendental, si se prefiere) de lo existente, su profunda lejanía con respecto al ideal al que debería responder o que debería, siquiera parcialmente, reflejar. La noción de «presupuestos idealizantes» (idealisierende Voraussetzungen) manejada por Habermas viene a reflejar la urgente necesidad de una re-idealización del espacio de reflexión filosófica. Tal cosa supone no seguir confundiendo razón transcendental con razón transcendente, por un lado, y, por otro, no seguir emborronando o tornando difusa la relación entre hechos y valores. En este sentido, el problema pragmático-transcendental por excelencia consiste precisamente en lograr dilucidar

si las huellas de una razón transcendental se pierden en la arena de la historización y la contextualización, o si una razón encarnada en los contextos históricos conserva la fuerza de una transcendencia desde dentro. $¿$ Conserva la cooperación de sujetos capaces de aprender dentro de sus respectivos mundos de la vida - articulados siempre de modo lingüístico - la fuerza revisora necesaria para un cambio racionalmente motivado de la interpretación del mundo? ¿Está la razón arrojada al acontecer «abridor del mundo» del lenguaje, o continúa siendo, al mismo tiempo, una fuerza «que mueve el mundo»? ${ }^{41}$.

En otro lugar tuvimos ocasión de tratar en detalle el asunto de la duplicidad de 
planos en que se desarrolla, con toda la tensión que ello comporta, la reflexión de Habermas $^{42}$. Se trata de destacar la existencia de un plano sociológico (PS) y un plano filosófico (PF) que mantienen entre sí una relación tal que la pervivencia del PS puede prescindir con toda naturalidad del PF, mientras que éste se ve en la obligación de mantener un problemático equilibrio entre hostilidad y proximidad con respecto a aquél. La raíz del problema, según esto, se encuentra en la profunda asimetría en que se hallan uno y otro plano en el marco de una situación pos-metafísica, donde el PS se mueve, por decirlo de un modo coloquial, como pez en el agua (relativismo, utilitarismo, indiferentismo ontológico) en tanto que el PF ha de sostenerse a sí mismo recurriendo problemáticamente (pues no puede echar mano de bases metafísicas) a fuentes lin guístico-normativas o fenomenológicas, a la vez que dibujándose a contraluz de las exigencias sistémicas e incluso coactivas del PS. Se trata, por decirlo así, de un combate entre dos ejércitos extraordinariamente desiguales.

La posición de Habermas puede resumirse en los siguientes cuatro puntos:

- El PF es el único plano que puede iluminar al PS desde un ángulo pragmático-transcendental.

- El PF sólo puede establecer una auto-fundamentación resistiendo a la tentación de apoyarse en y desarrollarse simplemente por medio de la negación retórica de PS.

- La tarea del PF consiste en mantener abierto un proceso de comunicación lingüística alimentando una constante ampliación del punto de vista de los miembros que intervienen en ella (mediante el recurso sistemático a los mejores argumentos).

- El único punto de apoyo motivacional con que cuenta el PF es la honradez de los hablantes, que han de comunicarse entre sí rechazando cualquier mecanismo coactivo o institucional (el Derecho, por ejemplo) y renunciando a la vez voluntariamente a conservar su natural egocentrismo como hablantes «situados» (embedded) justo en las antípodas del «velo de la ignorancia» rawlsiano.

Cuatro puntos, cuatro problemas. No son de extrañar en absoluto ni el constante titubeo habermasiano entre uno y otro plano (recurriendo en ocasiones al PS sin aclarar si en el marco del análisis pragmático constituye un punto de salida o un punto de llegada) ni el carácter contingente de una fundamentación empírica incapaz de superar por sus propios medios la lógica del «quien no quiere, no quiere» ${ }^{43}$.

La confusión entre el plano filosófico y el plano sociológico hace pronto su aparición, justo en el comienzo de la teorización habermasiana en torno al camino reflexivo necesario para la reelaboración de un planteamiento pragmático conectado con el giro lingüístico. [ $\mathrm{El}$ punto de conexión de uno y otro es, como sabemos, el hecho de considerar el enunciado de afirmaciones como un acto de habla que, pragmáticamente, supone determinados cambios en la conducta del hablante (Michael Dummet) y que, pragmáticotranscendentalmente, refleja su responsabilización a la hora de mantener ciertos compromisos morales con el contenido de las afirmaciones (Robert Brandom)]. La mencionada confusión entre planos viene a recaer en la indistinción entre una necesaria objetivación, hecha posible por el giro linguístico, de las actitudes de los agentes morales, que ahora son concebidos como hablantes cuya conducta verbal refleja no sólo síntomas de su conducta en general, sino también exigencias de una conducta moral por su parte, y una innecesaria reducción de las condiciones de validez del lenguaje normativo a las condiciones de aceptabilidad social de la emisión de textos y de actos de habla. Con 
esto quiere decirse que el abandono de aquel monologicismo atribuido a la filosofía de Kant en tanto que filosofía de la conciencia subjetiva no debería suponer, como si fuera un efecto colateral inevitable, el abandono de la tensión entre planos posibilitando la difuminación de fronteras entre «lo admisible» $\mathrm{y}$ «lo admisible racional». Abandonar la subjetividad no quiere decir abandonar la contrafacticidad. No obstante, parece que la renuncia habermasiana a atribuir una cierta naturaleza transcendente a la racionalidad humana parece conducir, como «por arrastre», a la negación de su naturaleza transcendental. Craso error, que se ve alimentado por el recurso a Wittgenstein y su concepción del lenguaje como juego convencionalmente reglamentado:

Según la concepción pragmático-formal, la estructura interna racional de la acción orienta$\mathrm{da}$ al entendimiento se refleja en las suposiciones que los actores tienen que adoptar cuando entran sin reservas [cursiva nuestra] en esta práctica. El carácter necesario de este «tener que» [eines solchen «Müssens»] ha de entenderse más bien en el sentido de Wittgenstein que en el de Kant, es decir, no en el sentido transcendental de las condiciones universales, necesarias e inteligibles (y sin origen) de la experiencia posible, sino en el sentido gramatical de la inevitabilidad que resulta de los nexos conceptuales internos de un sistema de comportamiento guiado por reglas en el que nos hemos socializado y que, en cualquier caso, resulta irrebasable para nosotros. Después del rebajamiento pragmatista del planteamiento kantiano, «análisis transcendental» significa la investigación de condiciones presuntamente universales pero sólo irrebasables de ipso, que deben ser satisfechas para que puedan producirse determinadas prácticas o resultados fundamentales ${ }^{44}$.

La presencia de unas idealizaciones necesarias previas - lógica, no genéticamente - a los actos de habla y encargadas de gobernarlos (en tanto que son actos de habla responsables) viene a garantizar precisamente la existencia de aquellas presuposiciones de la argumentación que mantienen en funcionamiento la dinámica de progresivo descentramiento de las perspectivas pluralistas de interpretación ${ }^{45}$;

lo que pone sobre la mesa la urgente necesidad de distinguir, como hace Gadamer, por ejemplo ${ }^{46}$, entre el uso de un lenguaje surgido de una convención y el uso de ese mismo lenguaje enfrentado a ella. Pues si tal confrontación representa el más genuino producto de una acción comunicativa llevada a cabo bajo condiciones ideales, entonces quiere decirse que el primer acto de habla responsable, la negación de los imperativos institucionales y sistémicos de la estructura social - si tal negación es dialógica o monológica resulta ahora indiferente $-{ }^{47}$ ha de consistir necesariamente en un alejamiento del contexto, en la cancelación de la propia lógica que lo rige, en el regreso a la conciencia capaz de autopercibirse como no completamente subsumida en el contexto de la comunicación social (es decir, capaz, por decirlo con las certeras palabras de Javier $\mathrm{Mu}$ guerza, de disentir, de decir no a las pretensiones de validez meramente social de tal contexto). Esto supondría una vuelta a planteamientos transcendentales, un distanciamiento social vertebrado a un con qué derecho digo, pienso y actúo (o decimos, pensamos y actuamos) de esta manera situado a contrapelo del contexto social. Habermas, que identifica sistemáticamente «monológico» con «subjetivo», considera éste un camino equivocado:

$\mathrm{La}$ independencia epistémica con respecto a la autoridad colectiva de la comunidad lingüística parece que sólo puede ser asegurada al individuo mediante una distancia monológica. Esta descripción individualista yerra lo esencial del entendimiento lingüístico. Las comunicaciones cotidianas tienen lugar en el contexto de supuestos de fondo compartidos, de modo que la necesidad de comunicación surge, sobre todo, cuando tienen que armonizarse las opiniones $e$ intenciones de sujetos que juzgan y 
deciden independientemente. La necesidad práctica de coordinar distintos planes de acción es lo que otorga un claro perfil a la expectativa que tienen los participantes en la comunicación de que los destinatarios tomen posición respecto de sus propias pretensiones de validez. Éstos esperan una reacción afirmativa o de rechazo que cuenta como respuesta, puesto que sólo el reconocimiento intersubjetivo de las pretensiones de validez criticables genera aquel tipo de comunidad sobre la que pueden fundarse para ambas partes vínculos fiables que tengan consecuencias relevantes para la interacción ${ }^{48}$;

lo que, en todo caso, al insistir en la necesidad de señalar un marco lingüístico irrebasable como condición sin duda necesaria para el entendimiento entre los agentes sociales (necesaria pero no suficiente a la hora de dar cuenta de la necesidad de superación del individualismo reflejado en esos agentes «que juzgan y deciden independientemente») puede resultar perfectamente compatible con el mantenimiento de una «lógica social» no dirigida, en principio, a ninguna superación dialógica del contexto (contexto que exige también, a su modo, la armonización de opiniones e intereses de los agentes sin que éstos tengan por qué preocuparse de la legitimidad pragmático-transcendental de sus respectivas posiciones: la sociedad democráticoliberal es un perfecto ejemplo de ello). Al igual que en Brandom, también parece darse en Habermas una confianza en el juego de dar y pedir razones en general, como si tal juego se orientara espontáneamente hacia una derivación transcendental. Puede, pero no tiene por qué. La comunicación fáctica ( «cotidiana») es condición necesaria para el establecimiento de una comunicación ideal, de acuerdo, pero ni es condición suficiente ni mucho menos - permite identificar una y otra. La cuestión de con qué derecho digo (y me comprometo con) esto o aquello apunta más allá de la simple «necesidad práctica" de la comunicación, superando «artificialmente» una lógica que, dejada a su libre desarrollo, más bien alimenta y reproduce una comunicación encerrada en los imperativos sistémicos de la sociedad existente (liberal). Cierto que Habermas ha afirmado que se trata de una comunicación «sin reservas» (literalmente überhaupt: en general, sin restricciones), pero que los hablantes tengan que presuponer un importante grado de sinceridad y de racionalidad no implica, dentro de una consideración simplemente pragmática de los actos de habla, que estén -o se sientan- moralmente obligados (Habermas emplea el verbo objetivo müssen, no el verbo subjetivo sollen) a que tal presuposición se desarrolle hasta el límite, sin reservas ni restricciones, a no ser mediante la activación del elemento pragmáticotranscendental de la honradez, cuya presencia supone precisamente la superación de un egocentrismo que, sin ella, puede perfectamente sobrevivir e ir tirando en el seno de una atribución de racionalidad «a medio gas».

No cabe duda de que el carácter monológico de la conciencia transcendental proviene del lenguaje como única estructura irrebasable capaz de albergar el juego de dar y pedir razones. En efecto, es evidente que, al surgir de una ruptura con el lenguaje instrumental (o retórico), el lenguaje contrafáctico proviene íntegramente de él y ha de combatir todas las limitaciones necesariamente heredadas de él. Pero es que, además, todo lenguaje contrafáctico ha de desarrollarse exclusivamente en un ámbito lingüistico abstracto $e$ independiente de toda intuición o comprobación, pues tiene que ver con valores, no con hechos. El lenguaje es, pues, omnipresente e irrebasable. Mas de ahí no se sigue que el desarrollo espontáneo de dar y pedir razones nos conduzca a una utilización honrada y sin reservas de tal juego, precisamente porque la superación del egocentrismo supone una operación interior, registrada en la conciencia, complicada y no pocas veces dolorosa, en donde, al te- 
ner que renunciar al perverso mecanismo del tu quoque (¿por qué he de ser honrado con Fulano si él no tiene la menor intención de serlo conmigo?), se viene a dar una especial situación de solipsismo: no tengo derecho a dejar de ser honrado con Fulano aunque no consiga una respuesta equivalente por su parte. De ahí proviene precisamente el muy especial estatuto de la conciencia monológica, su aferrarse a valores morales independientemente de la actitud instrumental de los demás. Ahí radica justamente la determinación de $l i$ bertad interior ostentada por ella.

La indistinción entre planos subyacente bajo algunas afirmaciones habermasianas (donde se identifican subjetividad y monologicidad, conciencia individual y conciencia transcendental) provoca una fuerte aporía en el interior de la reflexión, lo que obliga a Habermas a presuponer una equivalencia entre el juego social de dar y pedir razones y el juego moral de dar y pedir razones en el seno de una comunicación irrestricta y sin reservas. Naturalmente, la introducción de ese «sin reservas» supone la presencia imantadora de un valor contrapuesto a la comunicación fáctica registrada en el plano social (donde o bien se habla de hechos, o bien se parlotea ocultando las verdaderas intenciones del hablante, o bien se ponen de manifiesto «sinceramente» como una pieza integrante de la comunicación transformada en ese momento en simple bargaining, en simple negociación y forcejeo). En cualquier caso, o se recurre a un transcendental (honradez) que garantice $a$ priori la apertura del proceso de comunicación, o éste tiende a estancarse en un simple arreglo y solapamiento de intereses.

Es interesante observar, al hilo de todo esto, el reproche que Habermas dirige a Peirce y su noción de «opinión final» como aquel estado al que acabaría llegándose una vez que se consumara el proceso de apertura comunicativa. Se trata de un reproche que pone sobre la mesa, bien a la vista, el carácter ambiguo de la teoría del propio Habermas. La «opinión final» funciona en Peirce como un ideal regulativo que dirige, gobierna y mantiene constantemente abierto el proceso de comunicación a condición de que éste refleje la honradez de los hablantes, su hablar sin reservas. La validez incondicional de la pretensión de verdad cede al proceso una apariencia de clausura que en realidad nunca se verifica en el mundo de los hechos sociales. El sub-texto que funciona en Peirce afirma que en condiciones ideales se llegaría a una opinión final. Habermas fija su atención en esta clausura - de índole transcendental - y desarrolla su objeción en dos registros diferentes. Por un lado, sin haber descontaminado aún el término «verdad» de sus adherencias empiristas (lo que le lleva a emparentar «aseverabilidad» y «comprobación», desechando así con ello el propio término de «verdad» en el marco de un pensamiento contrafáctico). Mediante este reproche Habermas parece torpedear, no sólo contra Peirce, sino también contra sí mismo, la posibilidad de tránsito entre PS y PF. Por otro lado, constatando que el plano social no permite ningún género de clausura, lo que viene a traer consigo, como por arrastre, la permanente puesta en cuestión del propio plano filosófico. El asunto, por tanto, se resume en que no se sabe dónde apoyar entonces la diferencia entre un simple dar y pedir razones en general y dar y pedir razones honradas. $\mathrm{Ni}$ en uno ni en otro caso parece posible hablar de verdades morales, bien por no ser fácticas, bien por no poder definirse como «verdades conseguidas»:

El reflejo epistémico de la incondicionalidad es la revalorización ideal del público crítico en una instancia «última». Para ello utiliza Peirce la imagen de la comunidad de investigadores ilimitada en el tiempo histórico y en el espacio social, una comunidad que impulsa permanentemente el proceso inclusivo de 
investigación hasta el valor límite de la «opinión final» ${ }^{49}$.

Los elementos puestos en funcionamiento por Peirce («última instancia», «ilimitada» «permanentemente», «valor-límite») ponen de manifiesto con suficiente claridad el carácter kantiano de asíntota que caracteriza el proceso de comunicación ideal. El doble reproche de $\mathrm{Ha}$ bermas ${ }^{50}$ cae, pues, por su propio peso, puesto que su construcción de una comunicación registrada bajo condiciones ideales no sólo tiene que coincidir con el proyecto de Peirce, sino que, además, arranca en peores condiciones que éste al torpedear el plano transcendental que le permitiría despejar la ambigüedad existente entre una comunicación social fáctica y una comunicación ideal. Única forma de despejar tal ambigüedad: aceptar que la «verdad moral» no es una verdad definitivamente conseguible ni -mucho menosuna verdad empírica, sino una «verdad transcendental» que funciona precisamente como una necesaria presuposición idealizante, como una anticipación «cerrada» - en la idea- que permite pensar como posible y a la vez deseable la apertura honrada a una comunicación sin reservas.

Más breve: la verdad moral es $e l$ ideal regulativo de la comunicación.

La renuencia habermasiana a aceptar un planteamiento así (deudor, desde luego, de un fortísimo platonismo vertebrado en torno a un tercer «mundo ideal») le empuja, como ya se ha señalado varias veces, a intentar derivar la posibilidad de una comunicación ideal a partir de los presupuestos necesarios para una comunicación en general. Pero estos presupuestos son pragmáticos, no pragmático-transcendentales, pues una cosa es tener que suponer veracidad en mi interlocutor (mediante un razonamiento apagógico: «si no se supusiera veracidad en los hablantes nadie se pondría a hablar; de hecho hablamos todos los días con los demás, luego se supone dicha veracidad») y otra encontrar que es moralmente obligatorio para mí comportarme como un hablante honrado $\mathrm{y}$, por tanto, veraz ${ }^{51}$. El gran problema es que si se renuncia al monólogo como reflexión honrada del individuo consigo mismo, el único resorte motivacional a la hora de atribuir racionalidad a mi interlocutor resulta ser tan contingente como resultaba serlo en Brandom. Tampoco cabe esperar aquí otra cosa distinta a que el free rider lingüístico se avergüence de su actitud:

Para el comportamiento guiado por reglas, las reglas constitutivas abren continuamente la alternativa entre seguimiento de la regla y vulneración de la regla [...] Esto se muestra en el curso de la práctica. De la misma forma, sólo durante la acción comunicativa se hace patente quién defrauda la suposición pragmática de responsabilidad, quién «no juega» en absoluto. La necesaria suposición de racionalidad que se efectúa en la acción comunicativa sólo vale hasta nuevo aviso. Está expuesta al desmentido que pueda derivarse de las experiencias que realizan los participantes en esta práctica ${ }^{52}$.

Los aspectos motivacionales, sin embargo, con toda su carga negativa capaz de dejar al descubierto los flancos más débiles de la capacidad del lenguaje a la hora de inspirar conductas morales no deben apartarnos del nivel transcendental en que, siquiera incoativamente, ambigüedades al margen, viene a situarse Habermas. Y no sólo por cuestiones de método. También es posible esperar de este nivel un cierto tipo de aclaración conceptual de las intenciones de los hablantes en el sentido - de neta índole kantiana - de hacer recaer la responsabilidad de cualquier conducta inmoral en la capacidad de lenguaje del agente. La imparcialidad del juicio de cada individuo postulada por Kant no deja de influir poderosamente en Habermas (como en Brandom) a la hora de reconstruir, desde luego en un plano transcendental, los límites de la conciencia moral del agente. Según esto, la 
dimensión pragmática del lenguaje ya no fluye espontáneamente hacia su plasmación pragmático-transcendental, sino que se hace indispensable la introducción de un elemento problemático de decisión que recae exclusivamente en la responsabilidad del hablante. Con ello no se puede decir, desde luego, que obtengamos una solución definitiva del problema de la motivación moral, ni muchísimo menos, pero al menos salta por los aires el cerrojo liberal que suponía evidente, casi por medio de un mecanismo de «mano invisible», que los resultados de una instrumentalización del lenguaje vienen a tornarse, de un modo misterioso y sin transformarse ni un milímetro, en otras tantas optimizaciones de su uso moral. (El célebre «velo de la ignorancia» de Rawls cae bajo esta determinación. Al ser «de la ignorancia» se acerca al plano transcendental de la honradez, mas, al referirse exclusivamente a los intereses particulares de los agentes individuales, vuelve a situarse a la sombra de una construcción conceptual liberal). La exacerbación de una comunicación instrumental, pues, aun con todos los presupuestos pragmáticos a su favor, sólo ofrece como resultado más comunicación instrumental. No hay misteriosos saltos cualitativos. Quien se sirve del lenguaje y lo aprovecha para sus fines particulares: a) no está laborando «oscuramente» y sin saberlo para una misteriosa verticalización transcendental, sino que $b$ ) sabe perfectamente, y es responsable de, estar colaborando para la degradación del uso verdaderamente comunicativo del lenguaje.

Habermas acaba reconociendo la necesidad de suponer algo así como un eje «vertical» que refleje la existencia de un plano transcendental (PF) que consiga escapar de los requerimientos sistémicos de PS:

La pretensión de corrección o rectitud de los enunciados normativos se apoya en la presunta validez de una norma subyacente. A dife- rencia de la validez veritativa de los enunciados descriptivos, el ámbito de validez de una pretensión de corrección varía con el transfondo legitimador, es decir, varía en general con los límites de un mundo social. Únicamente los imperativos morales (las normas jurídicas que, como, por ejemplo, los derechos humanos, sólo se fundamentan moralmente) pretenden, como las afirmaciones, validez absoluta, es decir, reconocimiento universal. Ello explica la exigencia de Kant de que los imperativos morales válidos deben ser «universalizables». Las normas morales deben poder encontrar el reconocimiento racionalmente motivado de todos los sujetos capaces de lenguaje y de acción por encima de los límites históricos y culturales de cada particular mundo social ${ }^{53}$.

Tal reconocimiento universal (que, dicho así, parece hacernos regresar al nivel pragmático del PS: habría que especificar que tal reconocimiento es universal porque refleja una idea moral, esto es, porque merece ser universal) necesita de una actitud del agente que rompa con los cambiantes criterios sociales de lo bueno y lo malo, etc., lo que supone

a) la existencia de una posibilidad pragmática de anclar el sistema de motivaciones en el focus imaginarius de normas morales transcendentales, $y$

b) la plena responsabilización del agente que sabe que ha de dirigir su mirada al absoluto de un criterio pragmáticotranscendental;

que todo ello pueda traducirse exclusivamente en un plano social empírico y, a la manera de la «opinión final» de Peirce, se base en la toma en consideración de los intereses y argumentaciones de todos los agentes puede no garantizar la honradez - menos aún la racionalidad - de las deliberaciones y decisiones adoptadas, por ejemplo, a la hora de valorar el impacto negativo que una decisión adoptada según este criterio, necesario pero no suficiente, podría suponer en seres humanos aún no nacidos. 
Si un agente sabe que debería ajustar su conducta moral a un criterio pragmático-transcendental mediado lingüísticamente pero no por ello disuelto en los imperativos sistémicos del contexto, sabe también -o, al menos, es capaz de sospechar-que puede ser víctima de autoengaños y de ilusiones sociales que le hagan "ver" que tal contexto es irrebasable y racional (en sentido hegeliano). La presuposición habermasiana del deber de ser críticos ante a los propios engaños (insistimos: al menos en el sentido a priori de «estar en guardia» frente a ellos) ${ }^{54}$ tiene toda la apariencia de ser un texto autoinvalidante a no ser que se suponga $a$ prio$r i$ una capacidad de razonar por parte del agente que no quede plenamente subsumida en el contenido de tales autoengaños. Dicho de una manera muy coloquial, no hay por qué aceptar que estamos tan ciegos. Cierto que con respecto a un eje ideal encargado de representar el plano pragmático-transcendental de una comunicación honrada vienen a darse, casi sin excepción, constantes desviaciones y «trampas pragmáticas» más o menos conscientes, por lo que no cabe duda de que

un analista que no participara en el discurso podría captar estas desviaciones con respecto a una situación de habla que se supone aproximadamente «ideal» mucho mejor que los propios participantes implicados en el discurso. Pero éstos tampoco están tan enteramente absorbidos por esta implicación como para que ello impida que, incluso en actitud realizativa, sigan teniendo presente también - al menos intuitivamente - mucho sobre lo cual podrían llegar a tener, si adoptaran una actitud objetivante, un saber temático ${ }^{55}$

Mas si se plantean las cosas de esta manera (y así ha de ser si se desea superar «por arriba» la pegajosa omnipresencia de un lenguaje irrebasable), entonces no queda más remedio que postular un plano filosófico donde se albergan todas aquellas intuiciones a priori, contrafácticas, que constituyen, por decirlo así, el lado insobornable de la conciencia del hombre. Pues si siguen equiparándose irrebasabilidad formal e irrebasabilidad material - social - del lenguaje (o, en su traducción pragmática, entre consenso ideal y consenso fáctico), entonces toda la teoría habermasiana de la acción comunicativa se viene abajo. Por eso - ya para acabarresulta de la máxima importancia señalar lo que sigue a continuación:

a) La fundamentación de la teoría de la acción comunicativa como teoría pragmático-transcendental del uso del lenguaje es también, a su vez, una fundamentación pragmático-transcendental (algo así como un círculo lógico) ${ }^{56}$. En este sentido, se trata de enjuiciar qué sucede en la acción de los hombres $-\mathrm{y}$, en última instancia, en sus conciencias - cuando se postula y se defiende una teoría de la acción comunicativa, y sobre todo qué sucede cuando no se postula ni se defiende (muy parecido al asunto de los derechos humanos: su postulación y defensa son, sin duda, harto problemáticas, mas su ausencia resulta catastrófica) ${ }^{57}$.

b) Las evidentes insuficiencias motivacionales de la teoría de la acción comunicativa la limitan hasta el extremo de hacer de ella una teorización idealista difícilmente capaz de enraizar en los hechos cotidianos de habla ( $y$, por tanto, en la conducta de todos los días) ${ }^{58}$. La situación no puede resultar más interesante ni paradójica. Si se parte de la fundamentación pragmático-transcendental de dicha teoría propuesta en el punto $(a)$, la pregunta no es sólo en qué grado emancipa al hombre la postulación de una teoría de la acción comunicativa (cuya noción de «responsabilización» tantos puntos de contacto mantiene con el lema horaciano utilizado por Kant, sapere aude!), sino también, en el marco de una auto-aplicación de sus propios criterios transcendentales, con qué derecho postulamos una teoría emancipa- 
toria que, al renunciar a cualquier coacción que no sea el seguimiento de los mejores argumentos, se fundamenta en una más que problemática madurez que le permite, al final, caer en la tentación de retirarse, compungida, del mundo de los fenómenos sociales, con lo que de un idealismo «activo» pasamos a un idealismo «pasivo».

La formulación, por fortuna, puede ser mucho más breve y contundente (a condición de admitir una determinación «exterior» que fije su sentido real): la teoría de la acción comunicativa necesita de la presencia de un lenguaje legal que, a la manera de un arbotante, fije y proteja su estructura. Lo malo es que tal lenguaje viene a ser algo así como un «ayudante traidor» que impide, con su presencia, la realización de una verdadera actitud comunicativa al ser una plasmación específica - pero tan sagrada y oscura como la que más - de un lenguaje instrumental concebido, en su uso pragmático, para el engaño y el regateo (o, dicho coloquialmente, para «hacer ver lo blanco negro»). Aquí también $-\mathrm{y}$ esto es lo interesantesigue siendo Habermas un kantiano convencido. Los límites de su teorización moral coinciden, exactamente igual que en Kant, con el conocido «agujero jurídico», que prescribe, como suprema obligación moral, el cumplimiento de la ley positiva $^{59}$.
${ }^{1}$ Nos remitiremos a Robert B. Brandom, Articulating reasons. An introduction to inferentialism (en adelante $A R$ ), Cambridge, Harvard University Press, 2000 (trad. cast. La articulación de las razones. Una introducción al inferencialismo, Madrid, Siglo XXI, 2002); y a Jürgen Habermas, Kommunikatives Handeln und detranszendentalisierte Vernunft (en adelante $K H d V$ ), Stuttgart, Philipp Reclam, 2001 (trad. cast. Acción comunicativa y razón sin transcendencia, Barcelona, Paidós, 2002).

${ }^{2}$ Naturalmente la sensibilidad, tanto pura como empírica, constituye en Kant una importantísima fuente de conocimiento, sólo que ahí no se registra ninguna tensión interna, sino una contraposición entre la esfera general del fenómeno y la de la cosa en sí. No existe tensión en el sentido en que estamos usando aquí esta palabra por la sencilla razón de que sólo podemos percibir y concebir los fenómenos bajo las inevitables condiciones de la subjetividad humana.

3 «El idealista cree comprender y saber lo que sus temores y esperanzas le empujan a aceptar o creer. En realidad los únicos fundamentos de su actitud no son más que la comodidad y la vanidad», Kritik der reinen Vernunft, A 473/B 501.

4 «La verdadera sabiduría es la compañera de la sencillez, y como en ésta el corazón gobierna al entendimiento, normalmente convierte en superfluos los grandes preparativos de la erudición, pues no necesita de tales medios, que además nunca ejercen el mismo influjo en todos los hombres. Pues ¿qué?, ¿acaso es bueno ser virtuoso porque hay otro mundo o es buena la virtud por el hecho mismo de ser virtuosa?, ¿es que el corazón del hombre no contiene leyes morales en su interior y para animarlo en esa dirección ha de imaginarse la existencia de otro mundo?», Träume eines Geistersehers, erläutert durch Träume der Metaphysik, A 126.

${ }^{5} A R, 164$. Salvo indicación en contra, todas las cursivas son del autor.

6 Véase $A R, 189$

${ }^{7} A R, 76-77$.

8 Véase $A R, 59$,

${ }^{9} A R, 56$.

${ }^{10} A R, 63$.

" $A R, 101-102$. Recuérdese el célebre dictum kantiano acerca de la persuasión: «Puedo guardar para $\mathrm{m}$ la persuasión si me encuentro bien con ella, pero no puedo ni debo hacerla valer fuera de mín, Kritik der reinen Vernunft, A 822/B 850 .

${ }^{12}$ Las connotaciones políticas de la crítica al fiabilismo son evidentes. Al igual que Kant, Brandom esta sugiriendo que un discurso basado en meras «corazonadas» (por ejemplo, los discursos de los tiranos) carecen por completo de la legitimidad suministrada por la posibilidad de una consideración intersubjetiva de sus contenidos. Por eso resulta chocante que sea precisamente Sócrates el que afirme lo siguiente: «Sirviéndose de ella [la opinión exacta] gobiernan los hombres políticos los Estados, y no difieren en nada con respecto a conocimiento de los poetas y adivinos. Pues, en efecto, también ellos dicen por inspiración muchas verdades, pero sin saber nada de lo que dicen», Menón, 99b-c.

${ }^{13} A R, 38$. 
${ }^{14}$ Véase Carl G. Hempel, «Sobre la naturaleza de la verdad matemática», en James R. Newman (ed.), Matemática, verdad, realidad, Barcelona, Grijalbo, 1969 , pp. 12-32.

15 En realidad existe un compromiso previo e implícito, el de respetar las reglas de la lógica. Pero desde el punto de vista de lo que nos interesa ahora este compromiso es tan formal como el primero.

${ }^{16} \mathrm{AR}, 52$.

17 En cuanto al punto de vista lógico-formal, tam bién sería correcta la siguiente inferencia: si el ser humano tiene derecho a la alimentación y si no todos somos iguales (si no todos debemos ser considerados humanos, por ejemplo, los individuos pertenecientes a una raza diferente a la mía), entonces no todos tenemos derecho a la alimentación.

${ }^{18} A R, 63-64$.

${ }^{19} A R, 55$.

${ }^{20}$ Ciencia y valores, Barcelona, Destino, 2002.

${ }^{21}$ Op.cit., p. 193.

${ }^{22}$ Op. cit., p. 208

${ }^{23}$ Op. cit., pp. 205-206.

${ }^{24}$ Hablando del impacto social de las innovaciones tecnológicas - por ejemplo, la invención y utilización de misiles inteligentes - afirma Echeverría: «No hay que pensar que las valoraciones que se vayan a hacer de esas innovaciones sean las mismas para un general de la OTAN, un empresario aeronáutico, un político un telespectador o por quien recibe en su casa el impacto de un misil inteligente. Otro tanto cabría decir en otros ámbitos de la tecnociencia. El axiólogo ha de ser capaz de analizar las acciones, los resultados y las consecuencias desde todas esas perspectivas, poniéndose una y otra vez en el lugar del otro. Desde nuestro punto de vista no es posible hacer una axiología categórica y principialista, a la vista del enorme campo cubierto por los sistemas de valores tecnocientíficos», op. cit., p. 209

${ }^{25} A R, 61$.

${ }^{26}$ En inglés nígger, de connotaciones verdaderamente insultantes, frente al concepto descriptivo y neutro de black. En castellano la connotación negativa se introduce por medio del tono despectivo con que en ocasiones se emplea el término «negro».

${ }^{27} A R, 71-72$.

${ }^{28}$ Hemos desarrollado este punto en el contexto de una consideración pragmática y pragmático-transcendental de las ciencias sociales en Conocimiento, dominio y emancipación. La doble revolución de las ciencias sociales, Madrid, Fundamentos, 2002, pp. 9 y ss.

29 Véase en $A R, 82-84$ esta teorización de Brandom situada en el marco de una interesantísima distinción, tomada de Davidson, entre actuar con razones y actuar por razones. Por cierto, que nuestro Antonio Machado habla también, como de asunto digno de averiguación, de la diferencia entre actuar con creencias y actuar por creencias. Véase Antonio
Machado, Obras Completas, edición de Oreste Macrí, 2 vols., Madrid, Espasa Calpe, 1988, vol. 2 , p. 2339.

${ }^{30}$ Podría argumentarse que el racista puede convencer a una comunidad de racistas o de incautos, pero no a una comunidad racional. Pero una comunidad racional está compuesta de individuos que se dạn y se piden razones honradas, con lo que volveríamos a alejarnos de la laxa definición de dar y pedir razones en general ofrecida por Brandom. Más adelànte volveremos sobre este tema procurando extraer algunas consecuencias del interesante concepto brandomiano de «habilitación» (entitlement).

${ }^{31} A R, 94$.

${ }^{32} A R, 92$. La verdad es que por este camino es fácil llegar a la caricatura. Por ejemplo, podríamos llegar a considerar racional aprendernos de memoria el apellido de los habitantes de la provincia de Soria si ésta ha sido la condición ineludible puesta por un profesor para superar un examen importante. Al no distinguir los diferentes tipos de deber reteniendo exclusivamente la «racionalidad» de su acatamiento dejando de lado su racionalidad intrínseca, es decir, su legitimidad, Brandom parece quedarse sin un criterio que distinga suficientementè el juego de dar y pedir razones en general del de dar y pedir razones morales (honradas). Éste es precisamente uno de los principales reproches que Habermas dirige a este «realismo normativo» de Brandom. Véase Jürgen Habermas, «Von Kant zu Hegel. Zu Robert Brandoms Sprachpragmatik», en Wahrheit und Rechtfertigung. Philosophische Aufsätze, Frankfurt, Suhrkamp Verlag, 1999 , pp. 138-185.

${ }^{33} A R, 95$.

${ }^{34}$ Kant lo expresa lapidariamente; «El hecho de que no nos sea posible justificar las acciones afectadas por las inclinaciones ante la imparcialidad de nuestro propio juicio moral viene a demostrar que, pese a todo, reconocemos realmente la validez absoluta del imperativo categórico», Grundlegung zur Metaphysik der Sitten, B 58.

${ }_{35}$ Luis Martínez de Velasco, Hechos y valores. Una reivindicación de la conciencia, Madrid, Argés, 2000, pp. 44-64.

${ }^{36} A R, 190-191$

${ }^{37} A R, 192$.

${ }^{38} \mathrm{KHdV}, 10-11$.

39. Véase $K H d V, 10$

40 Véase $K H d V, 14$

${ }^{41} K H d V, 9$.

42 Véase Luis Martínez de Velasco, Hechos y valores, op. cit., pp. $25-43$.

43 «La comparación de la idea de libertad con la suposición de racionalidad no da para mucho. La racionalidad no es ninguna obligación [!]. Incluso con respecto al comportamiento moral o legal, la suposición de racionalidad no tiene el sentido de que el otro se sienta obligado a seguir la norma. Simplemente se 
le atribuye un saber respecto de lo que significa actuar autónomamente», $K H d V, 28$.

${ }^{44} \mathrm{KHdV}, 11-12$

${ }^{45} \mathrm{KHdV}, 81$.

46 Véase Hans Georg Gadamer, wie weit schreibt Sprache das Denken vor?», en Wahrheit und Methode 2, Tübingen, J.C.B. Mohr (Paul Siebeck), 1993, pp. 203 y ss.

${ }^{47}$ Indiferente en el sentido de que en el monólogo el individuo ha interiorizado la tensión entre hechos y valores, lo que supone que, aun hablando consigo mismo, el tal individuo ha superado la subjetividad. Desde luego que esto le empuja a hablar con los demás, pero querer dialogar responsablemente es un acto de conciencia individual.

${ }^{48} K H d V, 82-83$. Las cursivas son nuestras.

${ }^{49} \mathrm{KHdV}, 35-36$

50 «Esta imagen [de Peirce] es engañosa en do sentidos. Por una parte, sugiere que la verdad puede ser concebida como aseverabilidad justificada, siendo ésta, a su vez, medible en función de un consenso obtenido bajo condiciones ideales. Pero un enunciado encuentra el asentimiento de todos los sujetos racionales porque es verdadero, no es verdadero porque pueda constituir el contenido de un consenso ideal mente alcanzado Lipero aquí se está poniendo en juego entonces una verdad empírica!]. Por otra parte, esa imagen centra su atención no en el proceso de justificación en el curso del cual los enunciados verdaderos podrían resistir todas las objeciones, sino en el estado final de un acuerdo a prueba de revisión [tal estado final representa, en todo caso, la condición de posibi. lidad (por tanto, transcendental) que mantiene abierto el proceso de comunicación, es decir, la confianza en que por ese camino nuestros esfuerzos van bien dirigidos: sencillamente no hay contradicción entre una cosa y otra]», $K H d V, 36$

5) Veracidad y honradez, como hemos visto algo más arriba, no son exactamente lo mismo. Alguien puede ser veraz, incluso irrestrictamente veraz, y ser sincero e incluso cínico, pero no honrado.

${ }^{52} \mathrm{KHdV}, 32$.

${ }^{53} \mathrm{KHdV}, 41-42$

54 Véase $K H d V, 45-46$
${ }^{55} \mathrm{KHdV}, 46$.

${ }^{56}$ Círculo que, como tal, no resuelve el asunto de origen de la noción misma de «fundamentación pragmático-transcendental», eso es evidente. Mas lo que aquí nos interesa es precisamente captar qué encierra en su interior dicho círculo, es decir, qué persigue, cuál es su propia intención pragmático-transcendental. Observar el rendimiento moral de un planteamiento teórico, captar qué hace de nosotros, si nos hace o no mejores, $\mathrm{y}$ hacer de ello uno de los criterios que nos permite enjuiciarlo es una de las grandezas de Platón. Por ejemplo: «Creemos que es necesario buscar lo que no se sabe [en lugar de conformarnos con el argumento de que ni siquiera tiene sentido buscar lo que no se sabe precisamente porque no se sabe] para ser mejores, más esforzados y menos inoperantes que si creyéramos que no conocemos ni somos capaces de encontrar nada ni que es necesario buscar», Menón, 86b.

57 Este tipo de fundamentación apagógica desarrollada en el terreno pragmático-transcendental puede encontrarse, por ejemplo, en Karl-Otto Apel, «Konfliktlösung im Atomzeitalter als Problem einer Verantwortungsethik», en Diskurs und Verantwortung, Frankfurt, Suhrkamp Taschenbuch Wissenschaft, 1988, pp. 256 y ss.

58 Lo que, sin embargo, y por volver a la carga con lo último que hemos afirmado, no debe sonar a reproche en absoluto, pues el rendimiento pragmáticotranscendental de la teoría de la acción comunicativa (que - conviene recordar - no es una teoría descriptiva, sino normativa) consiste precisamente en mantener la tensión ser-deber ser mediante la apelación a la responsabilidad moral de los hablantes, cuya primera obligación es tomarse radicalmente en serio el lenguaje. En este sentido, una teorización igualmente idealista desde el punto de vista epistemológico como el «velo de la ignorancia» de Rawls ostenta un rendimiento pragmático-transcendental de menor intensidad (si cabe hablar así), pues más bien nos aquieta y nos reconcilia con el orden social existente a causa de su excesivo carácter «utópico».

${ }^{59}$ Por ejemplo, en Metaphysik der Sitten. Rechtslehre, A 34. 